\title{
Performance of Water-Based Zinc Oxide Nanoparticle Coolant during Abrasive Grinding of Ductile Cast Iron
}

\author{
M. M. Rahman ${ }^{1,2}$ and K. Kadirgama ${ }^{1}$ \\ ${ }^{1}$ Faculty of Mechanical Engineering, Universiti Malaysia Pahang, 26600 Pekan, Pahang, Malaysia \\ ${ }^{2}$ Automotive Engineering Centre, Universiti Malaysia Pahang, 26600 Pekan, Pahang, Malaysia \\ Correspondence should be addressed to M. M. Rahman; mustafizur@ump.edu.my
}

Received 6 November 2013; Revised 24 January 2014; Accepted 5 February 2014; Published 5 March 2014

Academic Editor: Young-Seok Shon

Copyright (c) 2014 M. M. Rahman and K. Kadirgama. This is an open access article distributed under the Creative Commons Attribution License, which permits unrestricted use, distribution, and reproduction in any medium, provided the original work is properly cited.

\begin{abstract}
This paper presents the performance of ductile cast iron grinding machining using water-based zinc oxide nanoparticles as a coolant. The experimental data was utilized to develop the mathematical model for first- and second-order models. The second order gives worthy performance of the grinding. The results indicate that the optimum parameters for the grinding model are $20 \mathrm{~m} / \mathrm{min}$ table speed and $42.43 \mu \mathrm{m}$ depth of cut for single-pass grinding. For multiple-pass grinding, optimization is at a table speed equal to $35.11 \mathrm{~m} / \mathrm{min}$ and a depth of cut equal to $29.78 \mu \mathrm{m}$. The model fit was adequate and acceptable for sustainable grinding using a $0.15 \%$ volume concentration of zinc oxide nanocoolant. This paper quantifies the impact of water-based $\mathrm{ZnO}$ nanoparticle coolant on the achieved surface quality. It is concluded that the surface quality is the most influenced by the depth of cut(s) and table speed.
\end{abstract}

\section{Introduction}

The automotive industry is one of the main users of ground components. Many solutions for grinding problems come from classical operations related to engine or transmission components. Classical examples are crankshaft grinding and camshaft grinding. Since the automotive industry is one of the major drivers for grinding development, it was chosen to be the focus of this study. Energy consumption by machining and grinding processes has not been a concern for industry because the energy cost is much lower than the other costs, such as materials, labor, and tooling [1]. The poor heat transfer properties of these conventional fluids pose serious problems to meet the present demands for miniaturization of systems and their effectiveness. Earlier efforts towards the improvement of the thermophysical properties of conventional fluids by the suspension of micron-sized metallic particles were not successful due to sedimentation, clogging, erosion and increased pressure drop in the flow channels of the heat exchangers, and so forth. A novel kind of heat transfer fluids known as "nanofluids" has significantly higher thermal conductivity compared to their base fluids. Nanofluids are expected to offer appreciable improvements in heat transfer capabilities [2]. Grinding is one of the most energy intensive among all machining processes. Grinding specific energy is typically higher than the energy required for melting the material. Considering the large amount of grinding operations used by industry worldwide, the impact can be significant when we can improve the energy efficiency of the grinding process. Furthermore, the high energy intensity of the grinding process is also the root cause of workpiece surface and subsurface damage, such as burn, white layer, and residual stresses, caused by the grinding operation [3]. Recent research has also shown how the finished surface quality imparted by a machining process may have significant impacts on other product life cycle stages besides manufacturing $[4,5]$. Thus, there is a need to change the manufacturing paradigm from minimizing resource costs to maximizing resource efficiency (i.e., maximizing production output or value added while minimizing resource inputs and costs) both in the manufacture and use of products [6]. There has been much research to understand the role of the grinding tool in the grinding process. Some expert systems exist where the grind process parameters [7] or the grinding tool $[8,9]$ can be chosen for certain applications. 
Sustainability in abrasive machining is a growing concern that has been recognized by both academia and industry [10-12]. However, the essential aspect of abrasive tool design and its impact on process ecoefficiency have not yet been examined from a holistic perspective. Nanofluids have the potential to be the next generation of coolants due to their significantly higher thermal conductivities. In grinding, to obtain performance the appropriate selection of a base fluid is very critical in the application of nanoparticle-based lubricants, as is proper selection of the cutting parameters for machining [13]. The thermal conductivity and the convection heat transfer coefficient of the fluid can be largely enhanced by the suspended nanoparticles [14]. The novel and advanced concepts of coolants offer intriguing heat transfer characteristics compared to conventional coolants. There is considerable research on the superior heat transfer properties of nanofluids, especially on the thermal conductivity and convective heat transfer. Eastman et al. [15], Liu et al. [16], Hwang et al. [17], Yu et al. [18], and Srinivasa Rao et al. [19] observed great enhancements of the nanofluids' thermal conductivity compared to conventional coolants. Enhancement of convective heat transfer was reported by Heris et al. [20], Kim et al. [21], Jung et al. [22], and Sharma et al. [23]. Tribological research found that lubricating oil with nanoparticles would exhibit friction reduction properties. Besides their application in industry, especially in heating and cooling, machining processes, lubrication, transportation, energy, and electronics, these features make nanofluids and nanoparticles useful and needing to be improved. The heat becomes concentrated in the grinding zone so that the workpiece is heated at high temperature and there is the possibility that the workpiece surface damage is due to the thermal effect [24]. However, there is little work on nanofluidbased coolants in grinding processes since this is a new thing and there is a lack of consistency in the results regarding thermal properties $[25,26]$. The objectives of this paper are to investigate the experimental performance of ductile cast iron using water-based $\mathrm{ZnO}$ nanocoolant and to develop mathematical models using the response-surface method.

\section{Materials and Method}

2.1. ZnO Nanofluid Preparation. Zinc oxide nanoparticle materials were selected because zinc is commonly added to the primary coolant to prevent corrosion. A two-step method was used to prepare the nanofluid. Basically nanoparticles are first produced as a dry powder, typically by inert-gas condensation, which involves the vaporization of a source material in a vacuum chamber and subsequent condensation of the vapor into nanoparticles through collisions with the controlled pressure of an inert gas such as helium. The resulting nanoparticles are then dispersed into a fluid in a second processing step. An advantage of this technique in terms of eventual commercialization of nanofluids is that the inert-gas condensation technique has already been scaled up to economically produce tonnage quantities of nanopowders. Thus, the dispersed nanoparticles which come in liquid form with a volume of one liter have $20 \%$ weight concentration with a 30-40 nm particle size, an $8.9 \mathrm{pH}$ level, and density equal to $5600 \mathrm{~kg} / \mathrm{m}^{3}$. It is diluted to a $0.15 \%$ volume concentration. The conversion of the weight percent concentration to volume concentration is expressed in (1). The second equation shows the dilution formula to determine how much distilled water is required to dilute the initial nanofluid. Consider

$$
\varphi_{1}=\frac{\omega \rho_{w}}{(\omega / 100) \rho_{w}+(1-(\omega / 100)) \rho_{\mathrm{ZnO}}},
$$

where $\varphi_{1}$ is the initial volume concentration, $\omega$ is the weight percent of nanoparticles, $\rho_{w}$ is the density of water, and $\rho_{\mathrm{ZnO}}$ is the density of the nanoparticles.

For a two-phase system, some important issues have to be faced. One of the most important issues is the stability of the nanofluids, and it remains a considerable challenge to achieve the desired stability of the nanofluids. To achieve stability in the dilution, the solution needs to be stirred continuously for one hour with the mixture set to $1000 \mathrm{rpm}$. Nanoparticles have a tendency to be aggregated. The use of surfactants is an important technique in enhancing the stability of nanoparticles in fluids. However, the functionality of the surfactants under high temperature is also a major concern, especially for high-temperature applications. Therefore, no surfactant is applied in this study.

2.2. Design of Experiments. The design of experiments (DOE) techniques enable designers to determine simultaneously the individual and interactive effects of many factors that could affect the output results. The statistical experimental designs (response-surface designs (RSM)) are most widely used in optimization experiments. The central composite design (CCD) is the most popular of the many classes of RSM designs due to the properties listed in Table 1.

A CCD can run sequentially. It can be naturally partitioned into two subsets of points: the first subset estimates linear and two-factor interaction effects while the second estimates curvature effects. The second subset need not be run when analysis of the data from the first subset indicates the absence of significant curvature effects. CCDs are also very efficient, providing much information on experimental variable effects and the overall experimental errors in a minimum number of required runs. They are very flexible. There is good commercial software available to help with designing and analyzing response-surface experiments. Table 1 shows the DOE table generated using statistical software. An experiment was conducted based on the DOE table and different types of coolant: zinc oxide $(\mathrm{ZnO})$ nanocoolant with a $0.15 \%$ volume concentration and a $5 \%$ volume concentration conventional soluble oil water-based coolant. Constant grinding wheels of vitrified bond aluminum oxide (PSA-60JBV) were used. Two types of grinding were considered: single pass and multiple pass set to ten passes. Figure 1 presents the different isometric views of workpiece. The dimensions of the workpiece are $80 \mathrm{~mm} \times 35 \mathrm{~mm} \times 20 \mathrm{~mm}$.

2.3. Grinding Process. The grinding process was undertaken using a Supertec precision grinding machine, model STP102ADCII. A vitrified bond aluminum oxide grinding wheel 
TABLE 1: Design of experiment.

\begin{tabular}{lcc}
\hline Specimen & Table speed $(\mathrm{m} / \mathrm{min})$ & Depth of cut $(\mu \mathrm{m})$ \\
\hline A & 20 & 20 \\
B & 20 & 40 \\
C & 20 & 60 \\
D & 30 & 20 \\
E & 30 & 40 \\
F & 30 & 60 \\
G & 40 & 20 \\
H & 40 & 40 \\
I & 40 & 60 \\
\hline
\end{tabular}
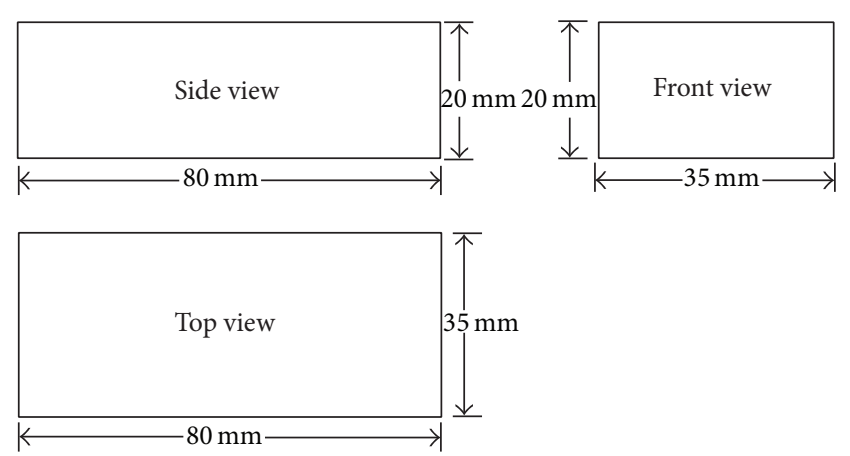

FIgURE 1: The workpiece and its different isometric views.

(PSA-60JBV) with an average abrasive size of 60 grains was used. The workpiece material was block ductile iron with a carbon content of 3.5-3.9\% and average hardness of 110Rockwell C. The width and length of the workpiece surface for grinding were $35 \mathrm{~mm}$ and $80 \mathrm{~mm}$, respectively. First, the workpiece was clamped onto a clamper jaw since cast iron is not attracted to the magnet field. Then the zero point of the $z$-axis was found by grinding the disc slowly until there were some sparks. After that, the coolant was sprayed directly onto the workpiece to ensure that the temperature of the workpiece was equivalent to the temperature of the coolant and as a precaution to achieve an exact value of rising temperature. Then the workpiece speed was calibrated using a tachometer. The model STP-102ADCII can be controlled and uses a hydraulic system to move left and right. The speed is controlled by a control valve; however, there is no speed display. So, in this research, calibration of the table speed using a tachometer had to be undertaken and the speed was set at $20 \mathrm{~mm} / \mathrm{min}, 30 \mathrm{~mm} / \mathrm{min}$, and $40 \mathrm{~mm} / \mathrm{min}$.

\section{Results and Discussion}

This section presents the performance characteristics of ductile cast iron grinding with a conventional coolant and a water-based zinc oxide nanocoolant. The mathematical models for the prediction of the material removal rate and tool wear rates are presented in this section. These models were developed using the accumulated data obtained from experiments using a conventional soluble oil coolant and

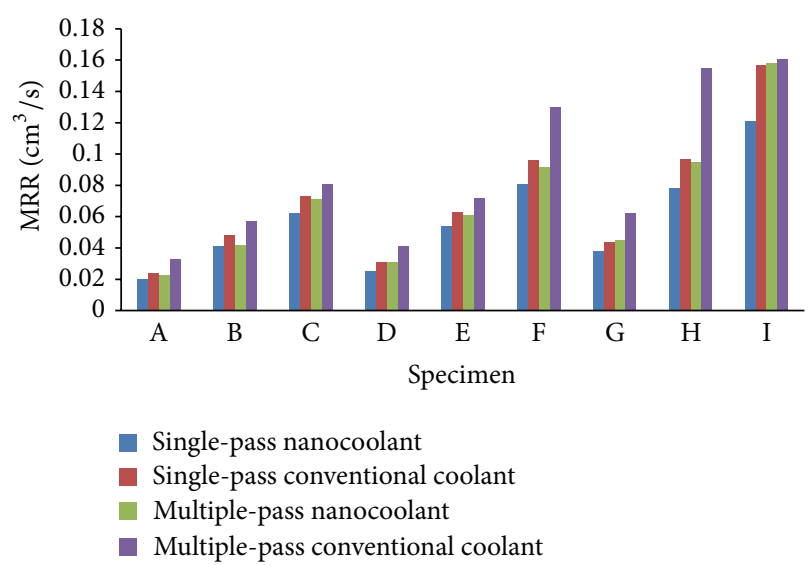

FIgURE 2: Material removal rate for each coolant and type of grinding.

a zinc oxide nanocoolant. The significance and adequacy of these models are verified by analysis of variance using the response-surface method.

3.1. Material Removal Rate. The material removal rate (MRR) for conventional coolant and nanocoolant, as well as for single and multipass grinding processes, is represented in Table 2. The experiments were conducted nine times with various combinations of table speed and depth of cut. A $5 \%$ volume concentration of soluble oil coolant and a $0.15 \%$ volume concentration of zinc oxide nanocoolant were used in this study. It can be observed that the minimum MRR in single-pass grinding using the conventional coolant was $0.024 \mathrm{~cm}^{3} / \mathrm{s}$; however, the minimum material removal rate was $0.020 \mathrm{~cm}^{3} / \mathrm{s}$ for the zinc oxide nanocoolant with the combination of the table speed and depth of cut. On the other hand, the maximum value is $0.155 \mathrm{~cm}^{3} / \mathrm{s}$ and $0.122 \mathrm{~cm}^{3} / \mathrm{s}$ for the conventional coolant and the zinc oxide nanocoolant, respectively. They were slightly different in multiple-pass grinding. The minimum MRR in multiple-pass grinding using a conventional coolant was $0.032 \mathrm{~cm}^{3} / \mathrm{s}$; however, the minimum MRR was $0.023 \mathrm{~cm}^{3} / \mathrm{s}$ for zinc oxide nanocoolant. Figure 2 shows the MRR value effect arising from various combinations of the factors, table speed, depth of cut, type of grinding, and type of coolant. Multiple-pass grinding has a higher MRR compared to the single pass due to the grinding wheel only passing over the specimen once. On the other hand, for multiple-pass grinding, the grinding wheel passes ten times.

However, when using zinc oxide nanocoolant, the MRR was slightly lower than that of the conventional coolant. This is due to the nanoparticle having exceptional tribological properties, which can reduce friction under extreme pressure conditions. This is supported by the findings from $\mathrm{Wu}$ et al. [27]. Analysis of variance (ANOVA) for the first order was undertaken to model and predict the MRR for single-pass grinding and multiple-pass grinding using zinc oxide nanocoolant and is presented in Table 2. The adequacy of the first-order model is verified using the $P$ value of 
TABLE 2: Material removal rate for each coolant and type of grinding.

\begin{tabular}{|c|c|c|c|c|c|c|}
\hline \multirow{3}{*}{ Specimen } & \multirow{3}{*}{ Table speed $(\mathrm{m} / \mathrm{s})$} & \multirow{3}{*}{ Depth of cut $(\mu \mathrm{m})$} & \multicolumn{4}{|c|}{ Material removal rate $\left(\mathrm{cm}^{3} / \mathrm{s}\right)$} \\
\hline & & & \multicolumn{2}{|c|}{ Single pass } & \multicolumn{2}{|c|}{ Multiple pass } \\
\hline & & & Conventional coolant & Nanocoolant & Conventional coolant & Nanocoolant \\
\hline A & 20 & 20 & 0.024 & 0.020 & 0.032 & 0.023 \\
\hline B & 20 & 40 & 0.049 & 0.041 & 0.056 & 0.045 \\
\hline $\mathrm{C}$ & 20 & 60 & 0.072 & 0.061 & 0.081 & 0.071 \\
\hline $\mathrm{D}$ & 30 & 20 & 0.031 & 0.025 & 0.041 & 0.031 \\
\hline $\mathrm{E}$ & 30 & 40 & 0.065 & 0.053 & 0.073 & 0.063 \\
\hline $\mathrm{F}$ & 30 & 60 & 0.096 & 0.081 & 0.105 & 0.093 \\
\hline G & 40 & 20 & 0.045 & 0.037 & 0.063 & 0.046 \\
\hline $\mathrm{H}$ & 40 & 40 & 0.096 & 0.079 & 0.112 & 0.095 \\
\hline I & 40 & 60 & 0.155 & 0.122 & 0.159 & 0.156 \\
\hline
\end{tabular}

TABLE 3: ANOVA results for first-order and water-based zinc oxide nanocoolant.

\begin{tabular}{lcccc}
\hline Source & Degree of freedom & Sum of sq. & $F$-static & $P$ value \\
\hline Model & 3 & 0.00824733 & 98.4364 & $<.0001$ \\
Error & 6 & 0.00016757 & & \\
C. total & $\mathbf{9}$ & $\mathbf{0 . 0 0 8 4 1 4 9 0}$ & & \\
Interaction & 2 & & & \\
Lack-of-fit & 5 & 0.00016307 & 7.2474 & 0.2745 \\
Pure error & 1 & 0.00000450 & & \\
Total & $\mathbf{6}$ & $\mathbf{0 . 0 0 0 1 6 7 5 7}$ & & \\
\hline & Multiple-pass grinding & & \\
Model & 5 & 19.60468930 & 262.3551 & $<.0001$ \\
Error & 4 & 0.14945158 & & \\
C. total & $\mathbf{9}$ & $\mathbf{1 9 . 7 5 4 1 4 0 8 8}$ & & \\
Interaction & 2 & & & \\
Lack-of-fit & 3 & 0.14878180 & 44.4271 & 0.1134 \\
Pure error & 1 & 0.00066978 & & \\
Total & $\mathbf{4}$ & $\mathbf{0 . 1 4 9 4 5 1 5 8}$ & & \\
\hline
\end{tabular}

the lack-of-fit. At a level of confidence of 95\%, the models were checked for their adequacy. Based on ANOVA, for the prediction of MRR in both single-pass and multiple-pass grinding using zinc oxide water-based nanocoolant, as shown in Table 3, the models are adequate due to the fact that the lack-of-fit of the $P$ values is insignificant where the value is 0.2745 for single-pass grinding and 0.1134 for multiplepass grinding, which are larger than 0.05 . This implies that both models could be of good fit and are adequate. Thus, the first-order linear equations used to predict the MRR in single- and multiple-pass grinding using zinc oxide waterbased nanocoolant are expressed as the following equations for single- and multiple-pass grinding, respectively:

$$
\begin{aligned}
\mathrm{MRR}_{\text {First-order single pass }}^{\prime}= & 0.0569+0.01933 x_{1} \\
& +0.03033 x_{2}+0.011 x_{1} x_{2},
\end{aligned}
$$

TABLE 4: ANOVA results for second-order and water-based zinc oxide nanocoolant.

\begin{tabular}{lcccc}
\hline Source & Degree of freedom & Sum of sq. & $F$-static & $P$ value \\
\hline Model & 5 & 0.00839245 & 291.6117 & $<.0001$ \\
Error & 4 & 0.00002245 & & \\
C. total & $\mathbf{9}$ & $\mathbf{0 . 0 0 8 4 1 4 9 0}$ & & \\
Interaction & 2 & & & \\
Lack-of-fit & 3 & 0.00001795 & 1.3298 & 0.5504 \\
Pure error & 1 & 0.00000450 & & \\
Total & $\mathbf{4}$ & $\mathbf{0 . 0 0 0 0 2 2 4 5}$ & & \\
\hline & Multiple-pass grinding & & \\
Model & 5 & 19.69133675 & 250.8286 & $<.0001$ \\
Error & 4 & 0.06280412 & & \\
C. total & $\mathbf{9}$ & $\mathbf{1 9 . 7 5 4 1 4 0 8 8}$ & & \\
Interaction & 2 & & & \\
Lack-of-fit & 3 & 0.06213434 & 30.9228 & 0.1313 \\
Pure error & 1 & 0.00066978 & & \\
Total & $\mathbf{4}$ & $\mathbf{0 . 0 6 2 8 0 4 1 2}$ & & \\
\hline
\end{tabular}

$$
\begin{aligned}
\mathrm{MRR}_{\text {Fist-order multipass }}^{\prime}= & 0.3914-1.71845 \cdot x_{1} \\
& +0.05564 x_{2}-0.084825 x_{1} x_{2} .
\end{aligned}
$$

Even though the first-order model was found to be adequate, the second-order model was postulated to extend the variables' range in obtaining the relationship between the MRR and the machining independent variables. The adequacy of the first-order model is verified using the $P$ value of lack-of-fit. At a level of confidence of $95 \%$, the models were checked for their adequacy. Based on ANOVA, the results for the prediction of MRR in both single-pass and multiplepass grinding using $0.15 \%$ volume concentration zinc oxide water-based nanocoolant are presented in Table 4 . The model is adequate due to the fact that the $P$ values of lack-of-fit are insignificant. The lack-of-fit value is 0.5504 for singlepass grinding and 0.1313 for multiple-pass grinding which are larger than 0.05 . This implies that both models are of good fit and are adequate. The second-order mathematical equation used to predict the MRR in single-pass and multiple-pass 


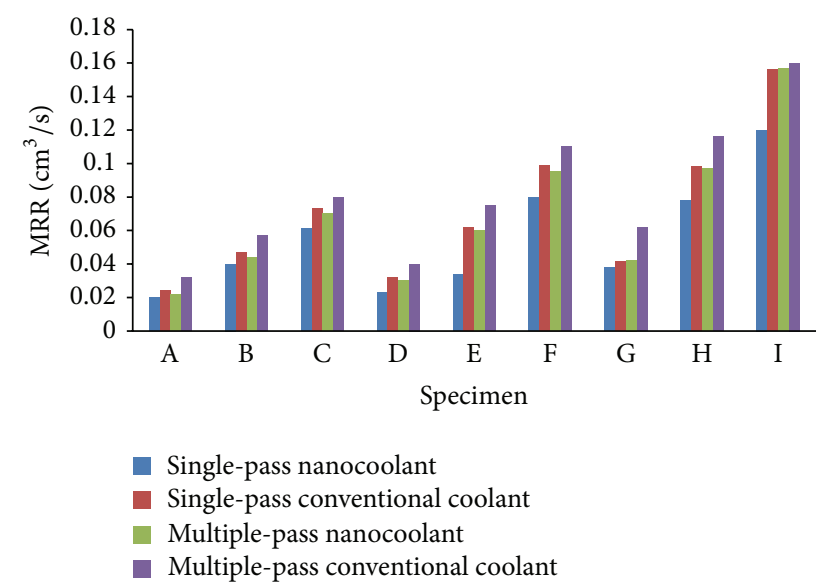

FIGURE 3: Comparison between the experimental and predicted results for both single- and multiple-pass grinding.

grinding for zinc oxide water-based nanocoolant can be expressed as the following equations, respectively:

$$
\begin{aligned}
\mathrm{MRR}_{2 \text { nd-order single pass }}= & 0.05193-0.019333 \cdot x_{1}+0.03033 x_{2} \\
& +0.011 x_{1} x_{2}+0.007643 x_{1}^{2} \\
& +0.0006429 x_{2}^{2} \\
\mathrm{MRR}_{2 \text { nd-order multipass }}= & 5.5109-1.7185 x_{1}+0.5564 x_{2} \\
& -0.08483 x_{1} x_{2}-0.120473 x_{1}^{2} \\
& -0.1282 x_{2}^{2} .
\end{aligned}
$$

To test whether the model is adequate and fit to predict the MRR in both single-pass and multiple-pass grinding, Figure 3 illustrates the relationship between the experimental and predicted values for both single- and multiple-pass grinding. The predicted values and measured values are closely related, indicating that the developed model could be effectively used to predict the MRR in both grinding processes in multiple-pass as well as single-pass grinding.

3.2. Tool Wear. Tool wear is usually the most relevant parameter inspected, as it has direct influence on the final product quality, the machine tool performance, and tool lifetime. During grinding, cutting wheels remove material from the workpiece to achieve the required shape, dimension, and surface roughness (finish). However, wear occurs during the grinding action and will ultimately result in the failure of the cutting wheel. When the tool wear reaches a certain level $(0.3 \mathrm{~mm})$, the tool or active edge has to be replaced to guarantee the desired cutting action. The tool wear was measured in mm using a Taylorsurf profilometer. Several readings were taken and the average was calculated. The readings were taken at several points and the average was calculated. Figure 4 illustrates the tool wear for zinc oxide nanocoolant and conventional coolant. In industry, tool wear

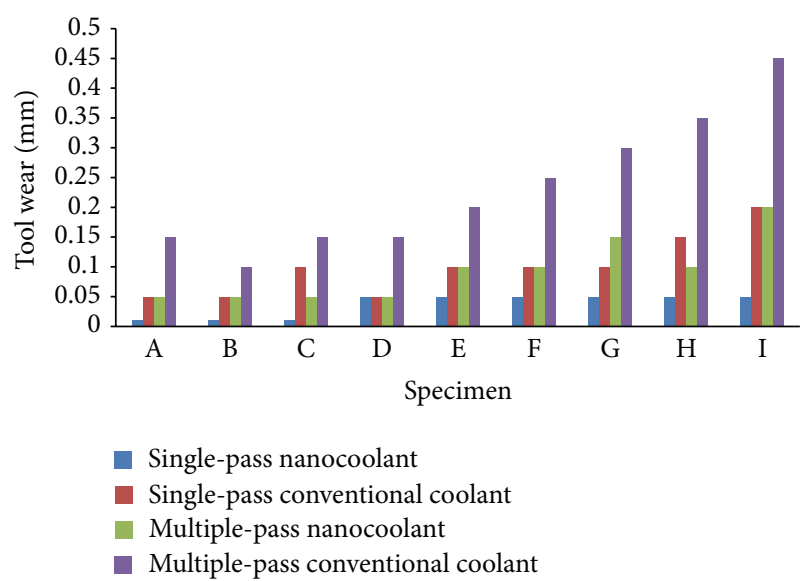

FIgURE 4: Tool wear for each coolant and type of grinding.

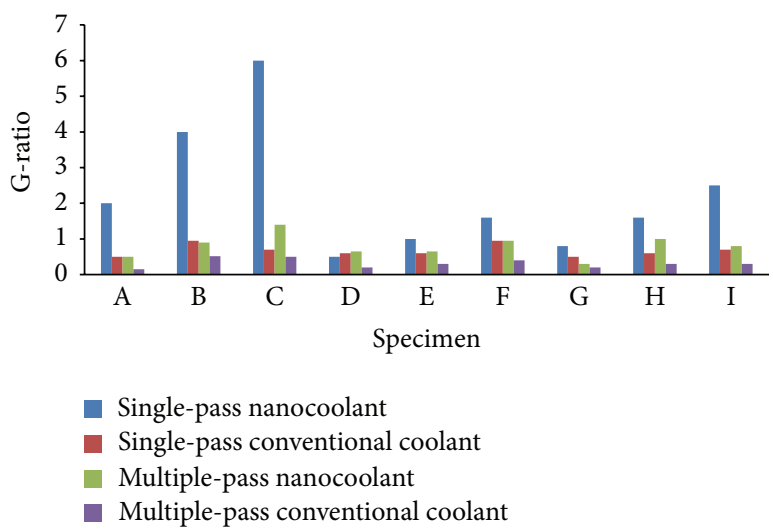

FIGURE 5: G-ratio for different coolants and types of grinding.

should be minimized to have a good quality finish, precision, and costing. It can be seen that the pattern of the wear increases as the depth of cut and table speed increase for multiple-pass grinding. The nanocoolant reduces the wear by almost $50 \%$ compared to the conventional coolant. This is due to the nanocoolant's reduced friction between the two contact surfaces.

3.3. G-Ratio. G-ratio is defined as the volume of work material removed divided by the volume of wheel wear. A high Gratio indicates a low wheel wear rate [28]. Figure 5 illustrates the G-ratio for different coolants and types of grinding. It can be observed that the type of coolant influences the Gratio as well as the type of grinding. Single-pass grinding generally exhibits a high G-ratio, as shown in Figure 5. The conventional coolant exhibits the worst wheel wear, that is, the lowest G-ratio. The G-ratio increases with the increase in the nanocoolant due to the formation of the slurry layer, which can protect the grinding wheel from grind/bond fracture. The nanocoolant enhances the thermal conductivity and convective heat transfer coefficient of the coolant, which exhibits improved load-carrying capacity and antiwear and friction reduction properties [27]. 


\section{Conclusion}

(1) The grinding of ductile cast iron using $\mathrm{Al}_{2} \mathrm{O}_{3}$ wheels under water-based zinc oxide nanocoolant and conventional coolant was studied.

(2) Compared to the water-based nanocoolant, tool wear could be substantial compared to conventional coolant. However, nanocoolant could achieve the same MRR without increasing the grinding forces.

(3) During nanocoolant grinding, a dense and hard slaggy layer was found on the wheel surface and could benefit the grinding performance.

(4) Nanoparticles reduce the friction of the grinding wheel and workpiece. Less friction leading to low heat density generates and minimizes the tool wear.

(5) Experimental results showed that the G-ratio could be improved with high concentrations of nanocoolant. Thus, the study of grinding using water-based nanocoolant focuses on advanced lubrication properties.

(6) Furthermore, forthcoming work will investigate the machining parameters necessary for optimal quality to determine the manufacturing resource costs required to maximize efficiency.

\section{Conflict of Interests}

The authors declare that there is no conflict of interests regarding the publication of this paper.

\section{Acknowledgments}

The authors would like to thank Universiti Malaysia Pahang for financial support under University Research Project no. RDU120310. The authors also thank Mr. Shabaruddin for his help and for preparing the workpiece during the experimental work.

\section{References}

[1] V. Kumar and J. W. Sutherland, "Sustainability of the automotive recycling infrastructure: review of current research and identification of future challenges," International Journal of Sustainable Manufacturing, vol. 1, no. 1-2, pp. 145-167, 2008.

[2] A. M. Hussein, R. A. Bakar, K. Kadirgama, and K. V. Sharma, "Experimental measurements of nanofluids thermal properties," International Journal of Automotive and Mechanical Engineering, vol. 7, pp. 850-863, 2013.

[3] S. Malkin and C. Guo, Grinding Technology: Theory and Applications of Machining with Abrasives, Industrial Press, New York, NY, USA, 2008.

[4] M. Helu, A. Vijayaraghavan, and D. Dornfeld, "Evaluating the relationship between use phase environmental impacts and manufacturing process precision," CIRP Annals-Manufacturing Technology, vol. 60, no. 1, pp. 49-52, 2011.

[5] R. M'Saoubi, J. C. Outeiro, H. Chandrasekaran, O. W. Dillon Jr., and I. S. Jawahir, "A review of surface integrity in machining and its impact on functional performance and life of machined products," International Journal of Sustainable Manufacturing, vol. 1, no. 1-2, pp. 203-236, 2008.

[6] R. Neugebauer, R. Wertheim, and C. Harzbecker, "Energy and resource efficiency in the metal cutting industry," in Proceedings of the 8th Global Conference on Sustainable Manufacturing, pp. 247-257, 2011.

[7] W. B. Rowe, "A generic intelligent control system for grinding," Computer Integrated Manufacturing Systems, vol. 10, no. 3, pp. 231-241, 1997.

[8] W. B. Rowe, Y. Li, X. Chen, and B. Mills, "An intelligent multiagent approach for selection of grinding conditions," CIRP Annals-Manufacturing Technology, vol. 46, no. 1, pp. 233-238, 1997.

[9] P. Shore, O. Billing, and V. Puhasmagi, "A standard grinding wheel assessment method to support a sophisticated grinding knowledge based system," Key Engineering Materials, vol. 257258, pp. 285-290, 2004.

[10] B. Denkena, M. Reichstein, N. Kramer, J. Jacobsen, and M. Jung, "Eco- and energy-efficient grinding processes," Key Engineering Materials, vol. 291-292, pp. 39-44, 2005.

[11] F. Klocke, B. Linke, B. Meyer, and A. Roderburg, "Sustainability aspects in centerless grinding," in Proceedings of the Conference of Sustainable Life in Manufacturing (SLIM '10), pp. 1-11, Egirdir, Turkey, June 2010.

[12] J. B. Araujo and J. F. G. Oliveira, "Evaluation of two competing machining processes based on sustainability indicators. Leveraging technology for a sustainable world," in Proceedings of the 19th CIRP Conference on Life Cycle Engineering, pp. 317-322, Berkeley, Calif, USA, May 2012.

[13] P. Hryniewicz, A. Z. Szeri, and S. Jahanmir, "Application of lubrication theory to fluid flow in grinding-part II: influence of wheel and workpiece roughness," Journal of Tribology, vol. 123, no. 1, pp. 101-107, 2001.

[14] S. Malkin and C. Guo, "Thermal analysis of grinding methodology: 1966-1988," Technometrics, vol. 31, pp. 137-153, 2007.

[15] J. A. Eastman, U. S. Choi, L. J. Thompson, and S. Lee, "Enhanced thermal conductivity through the development of nanofiuids," Materials Research Society, Symposium-V, vol. 457, pp. 3-11, 1996.

[16] M.-S. Liu, M. C.-C. Lin, I.-T. Huang, and C.-C. Wang, "Enhancement of thermal conductivity with $\mathrm{CuO}$ for nanofluids," Chemical Engineering and Technology, vol. 29, no. 1, pp. 7277, 2006

[17] Y. Hwang, H. S. Park, J. K. Lee, and W. H. Jung, "Thermal conductivity and lubrication characteristics of nanofluids," Current Applied Physics, vol. 6, no. 1, pp. e67-e71, 2006.

[18] W. Yu, H. Xie, L. Chen, and Y. Li, "Investigation of thermal conductivity and viscosity of ethylene glycol based $\mathrm{ZnO}$ nanofluid," Thermochimica Acta, vol. 491, no. 1-2, pp. 92-96, 2009.

[19] G. Srinivasa Rao, K. V. Sharma, S. P. Chary et al., "Experimental study on heat transfer coefficient and friction factor of $\mathrm{Al}_{2} \mathrm{O}_{3}$ nanofluid in a packed bed column," Journal of Mechanical Engineering and Sciences, vol. 1, pp. 1-15, 2011.

[20] S. Z. Heris, M. N. Esfahany, and S. G. Etemad, "Experimental investigation of convective heat transfer of $\mathrm{Al}_{2} \mathrm{O}_{3}$ /water nanofluid in circular tube," International Journal of Heat and Fluid Flow, vol. 28, no. 2, pp. 203-210, 2007.

[21] D. Kim, Y. Kwon, Y. Cho et al., "Convective heat transfer characteristics of nanofluids under laminar and turbulent flow conditions," Current Applied Physics, vol. 9, no. 2, pp. e119-e123, 2009. 
[22] J.-Y. Jung, H.-S. Oh, and H.-Y. Kwak, "Forced convective heat transfer of nanofluids in microchannels," International Journal of Heat and Mass Transfer, vol. 52, no. 1-2, pp. 466-472, 2009.

[23] K. V. Sharma, L. S. Sundar, and P. K. Sarma, "Estimation of heat transfer coefficient and friction factor in the transition flow with low volume concentration of $\mathrm{Al}_{2} \mathrm{O}_{3}$ nanofluid flowing in a circular tube and with twisted tape insert," International Communications in Heat and Mass Transfer, vol. 36, no. 5, pp. 503-507, 2009.

[24] R. Komanduri, W. R. Reed Jr., and B. F. Von Turkovich, "A new technique of dressing and conditioning resin bonded superabrasive grinding wheels," CIRP Annals-Manufacturing Technology, vol. 29, no. 1, pp. 239-243, 1980.

[25] M. Mahendran, G. C. Lee, K. V. Sharma, and A. Shahrani, "Performance of evacuated tube solar collector using waterbased Titanium Oxide $\left(\mathrm{TiO}_{2}\right)$ nanofluid," Journal of Mechanical Engineering and Sciences, vol. 3, pp. 301-310, 2012.

[26] K.-F. V. Wong and T. Kurma, "Transport properties of alumina nanofluids," Nanotechnology, vol. 19, no. 34, Article ID 345702, 2008.

[27] J.-H. Wu, B. S. Phillips, W. Jiang, J. H. Sanders, J. S. Zabinski, and A. P. Malshe, "Bio-inspired surface engineering and tribology of $\mathrm{MoS}_{2}$ overcoated cBN-TiN composite coating," Wear, vol. 261, no. 5-6, pp. 592-599, 2006.

[28] L. R. Silva, E. C. Bianchi, R. E. Catai, R. Y. Fusse, T. V. França, and P. R. Aguiar, "Study on the behavior of the Minimum quantity lubricant-MQL technique under different lubricating and cooling conditions when grinding ABNT 4340 steel," Journal of the Brazilian Society of Mechanical Sciences and Engineering, vol. 27, no. 2, pp. 192-199, 2005. 

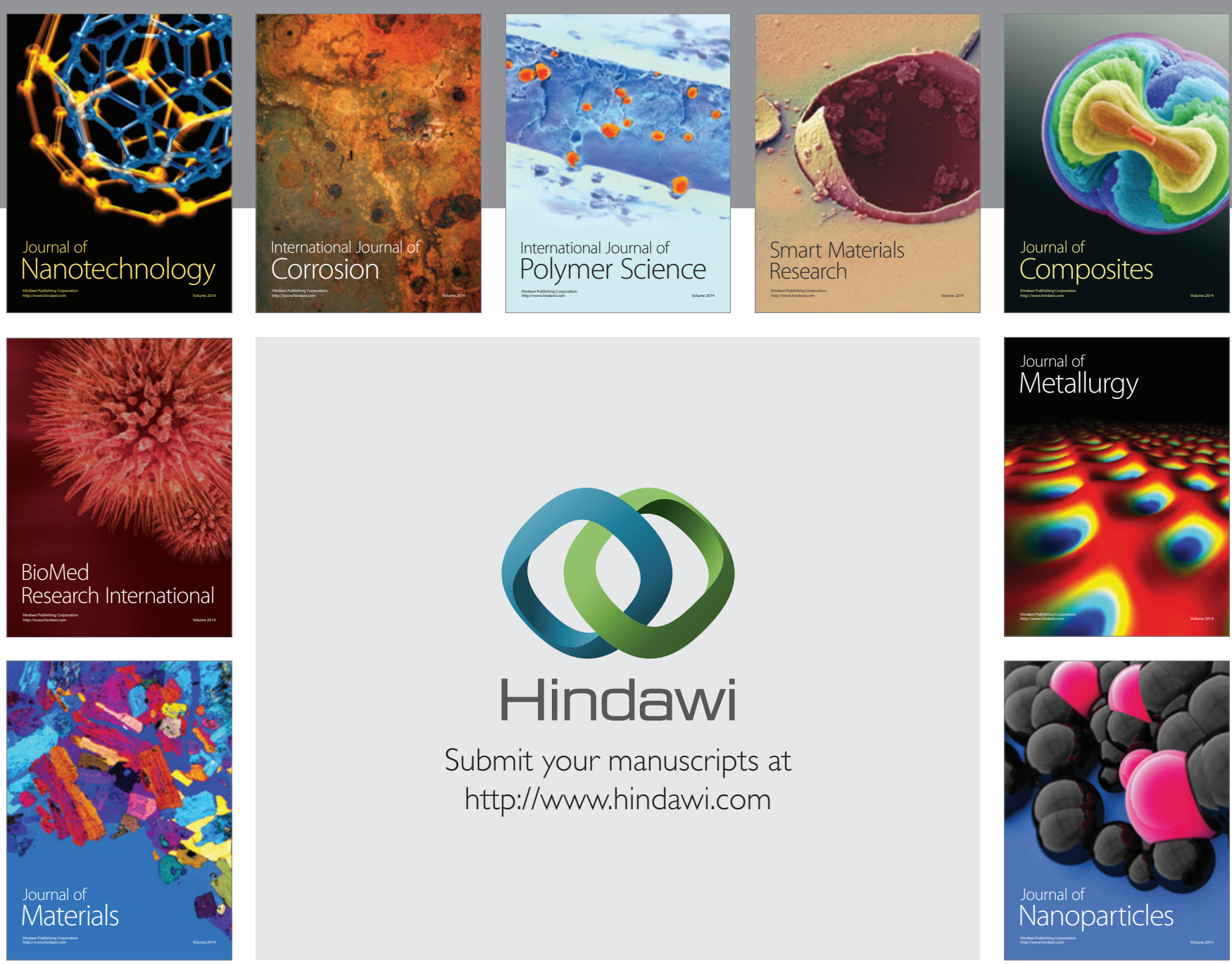

Submit your manuscripts at http://www.hindawi.com
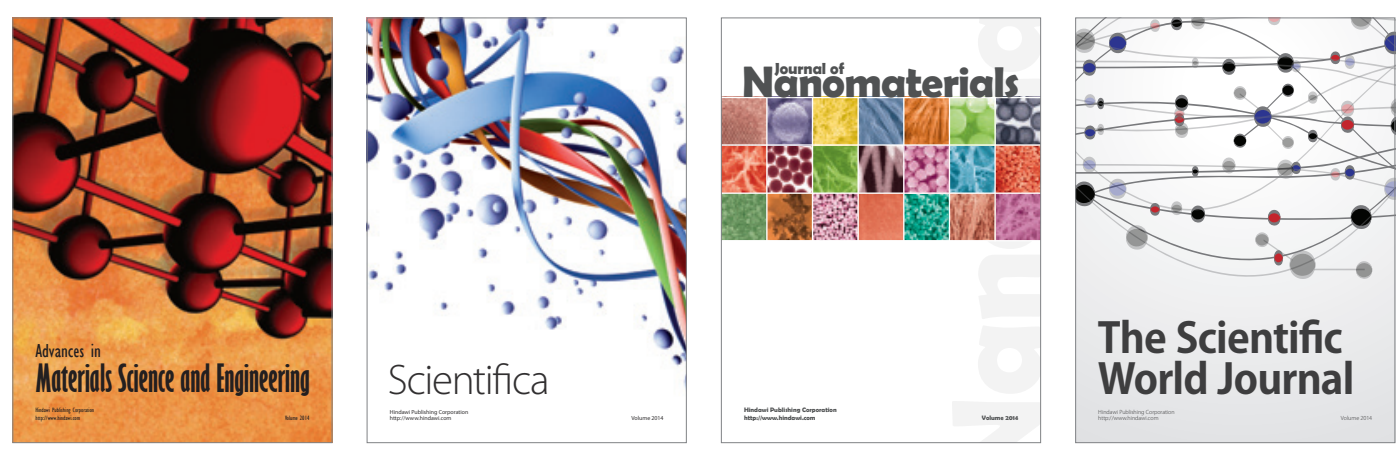

\section{The Scientific World Journal}
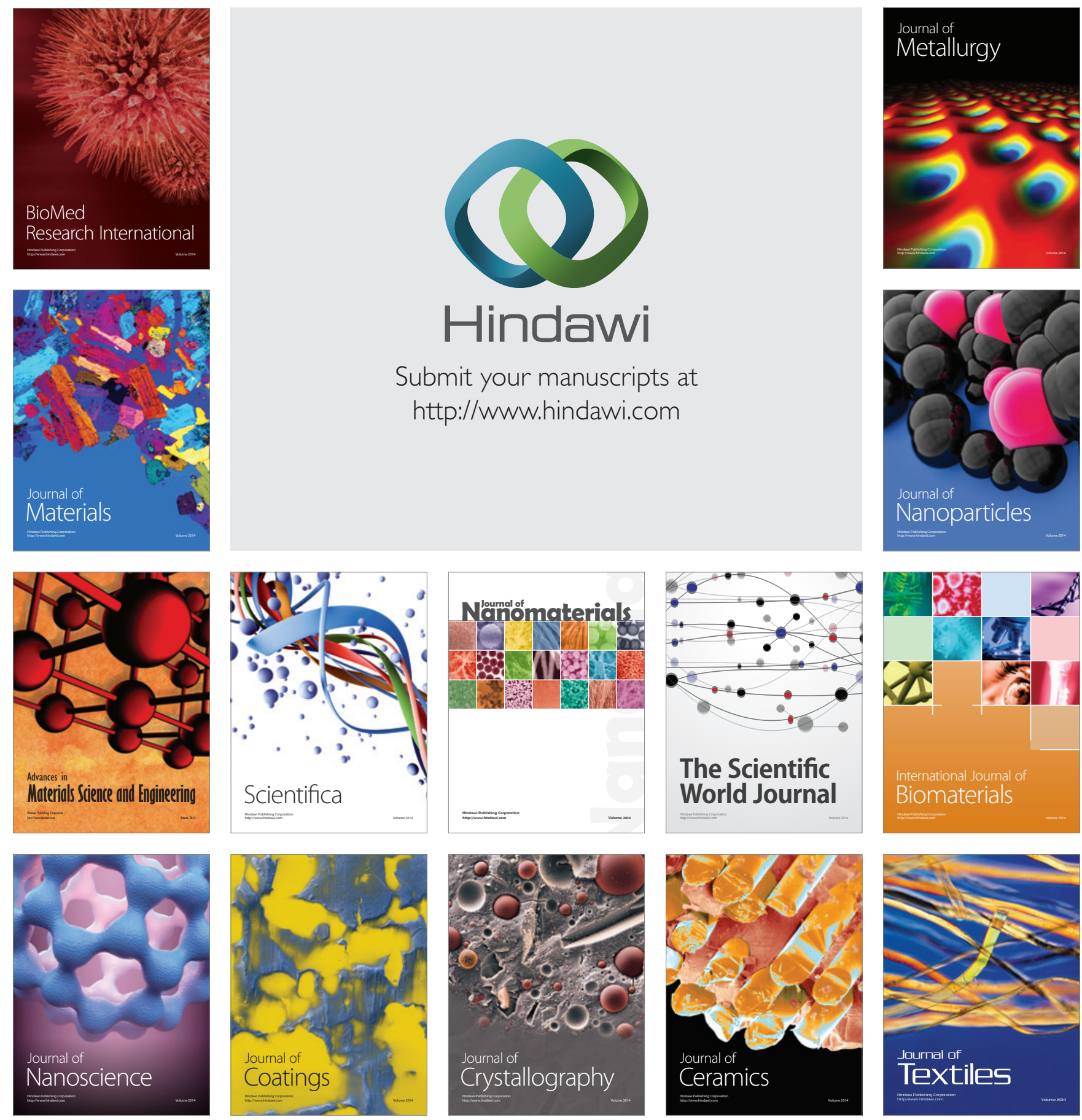